\title{
Exposição de fibroblastos de pterígios recidivados e da cápsula de Tenon normal à triancinolona
}

\author{
Exposure of recurrent pterygium and normal Tenon's capsule fibroblasts to triamcinolone \\ Magda Massae Hata Viveiros ${ }^{1}$, Dalton Kitakawa ${ }^{1}$, Clodomir S. C. de Carvalho ${ }^{2}$, João Candeias ${ }^{3}$, Carlos Roberto Padovani ${ }^{4}$, Silvana Artioli Schellini ${ }^{1}$
}

\section{RESUMO}

Objetivo: Avaliar a taxa de proliferação de fibroblastos provenientes de pterígios recidivados e da cápsula de Tenon normal, quando expostos in vitro à triancinolona.

Métodos: Foram realizadas culturas primárias de explantes de pterígios recidivados e da cápsula de Tenon normal do mesmo portador do pterígio. Os fibroblastos foram cultivados e subcultivados até a terceira passagem e posteriormente expostos à triancinolona, com avaliação da taxa de proliferação celular após três, seis, 12 e 18 dias.

Resultados: Os fibroblastos expostos à triancinolona apresentaram taxa de proliferação significativamente menor $(P<0,05)$ se comparados aos não expostos quando a avaliação foi feita após três, seis e 12 dias. Na avaliação do $18^{\circ}$ dia houve retomada da taxa de proliferação, com significância estatística, somente nos fibroblastos provenientes de pterígios.

Conclusão: Tanto os fibroblastos provenientes da cápsula de Tenon normal, quanto os de pterígios recidivados, apresentaram taxa de proliferação significativamente menor após a exposição à triancinolona. Os fibroblastos de pterígio retomaram a proliferação após 18 dias da exposição. Os resultados apontaram que a triancinolona pode ser útil como adjuvante no tratamento do pterígio.

Descritores: Pterígio/patologia; Fibroblastos/patologia; Fibroblastos/efeitos de drogas; Técnicas de cultura de células; Proliferação de células/efeitos de drogas; Recidiva; Triancinolona/farmacologia; In vitro

\section{ABSTRACT}

Purpose: To evaluate the proliferation rate of recurrent pterygium and normal Tenon's capsule fibroblasts after exposure to triamcinolone.

Methods: Explants of recurrent pterygia and normal Tenon's capsule of the same carrier were cultured. The fibroblasts were cultured and subcultured until the third passage and subsequently exposed to triamcinolone. The cell proliferation rate was evaluated 3, 6, 12 and 18 days after the exposure.

Results: Fibroblasts exposed to triamcinolone had significantly lower proliferation rate $(P<0.05)$ compared to those not exposed, when the evaluation was performed 3, 6 and 12 days later. In the $18^{\text {th }}$ day after exposure, there was a return in the proliferation rate, with statistical significance, only in the pterigyum fibroblasts.

Conclusion: Both the fibroblasts from normal Tenon's capsule as from recurrent pterygia showed significantly lower proliferation rate after exposure to triamcinolone. After 18 days from the exposition, pterygium fibroblasts recovered the proliferation. The results suggested the triamcinolone might be useful as adjuvant in pterygium treatment.

Keywords: Pterygium/pathology; Fibroblasts/pathology; Fibroblasts/drug effects; Cell culture techniques; Cell proliferation/drug effects; Recurrence; Triamcinolone/pharmacology; In vitro

\section{INTRODUÇÃO}

O receio da recidiva do pterígio após exérese, leva ao uso de medicações adjuvantes. A triancinolona é um corticosteroide potente, de depósito, que atua inibindo a síntese de prostaglandinas e leucotrienos, com consequente efeito anti-inflamatório. Utilizada há anos em vários campos da medicina, a triancinolona é um corticosteroide que vem sendo utilizado na Oftalmologia recentemente, no tratamento de inflamações intraoculares, edema macular associado à pseudofacia, retinopatia diabética, oclusão de veia central da retina, vasculites retinianas e membrana neovascular sub-retiniana de várias etiologias. Efeitos adversos significativos, tais como, catarata, hipertensão ocular, descolamento de retina e endoftalmite, já foram relatados ${ }^{(1)}$.
Porém, pouco ainda se sabe sobre o uso da triancinolona como medicamento adjuvante no tratamento do pterígio, o que motivou o presente estudo, realizado com o objetivo de avaliar a atividade proliferativa dos fibroblastos da cápsula de Tenon, provenientes de explantes de pterígios recidivados, em cultura de células, comparando-os com a atividade proliferativa dos fibroblastos da cápsula de Tenon normal, quando expostos à triancinolona.

\section{MÉTODOS}

Este é um estudo prospectivo, controlado, duplo-cego, aprovado pela Comissão de Ética em Pesquisa em Seres Humanos e executado na Faculdade de Medicina de Botucatu-UNESP, tendo a participação

2 Médico, Setor de Catarata, Departamento de Oftalmologia, Otorrinolaringologia e Cirurgia de Cabeça e Pescoço da Faculdade de Medicina de Botucatu, Universidade Estadual Paulista "Júlio Mesquita Filho" - UNESP - Botucatu (SP), Brasil.

3 Professor, Departamento de Microbiologia e Imunologia, Instituto de Biociências da Faculdade de Medicina de Botucatu, Universidade Estadual Paulista "Júlio Mesquita Filho" - UNESP - Botucatu (SP), Brasil.

${ }^{4}$ Professor, Departamento de Bioestatística do Instituto de Biociências, Faculdade de Medicina de Botucatu, Universidade Estadual Paulista "Júlio Mesquita Filho" - UNESP - Botucatu (SP), Brasil.

Financiamento: Estudo realizado com Auxílio Pesquisa oferecido pela Fundação de Amparo à Pesquisa do Estado de São Paulo (FAPESP).

Divulgação de potenciais conflitos de interesse: M.M.H.Viveiros, Nenhum; D.Kitakawa, Nenhum; C.S.C.de Carvalho, Nenhum; J.Candeias; Nenhum; C.R.Padovani, Nenhum; S.A.Schellini, Nenhum.

Endereço para correspondência: Silvana Artioli Schellini. DEP. OFT/ORL/CCP - Faculdade de Medicina de Botucatu - UNESP - Botucatu - SP - 18618-970 - Brasil E-mail: sartioli@fmb.unesp.br

Projeto número OF.408/2002, aprovado pelo Comitê de Ética em Pesquisa da Faculdade Medicina de Botucatu - UNESP, Botucatu (SP), Brasil. 
de 14 portadores de pterígio recidivado, todos localizados no setor nasal. Os pterígios foram removidos cirurgicamente, sendo retirados fragmentos da cápsula de Tenon da região do corpo do pterígio e fragmentos da cápsula de Tenon normal, localizada no fórnice temporal inferior, do mesmo olho acometido. Por este motivo, a existência de pterígio temporal foi considerada critério de exclusão.

O primeiro espécime a ser removido foi o tecido são, seguindo-se da cirurgia para exérese da lesão. Em seguida, procedeu-se a remoção de um fragmento da Tenon normal, obtida do fundo-desaco inferior do mesmo olho. Imediatamente após a remoção, os fragmentos de cápsula de Tenon foram acondicionados em tubos Ependorff estéreis e hermeticamente fechados e estocados à temperatura de $5^{\circ} \mathrm{C}$, para transporte em período inferior a 3 horas após a coleta, para o Laboratório de Imunologia do Departamento de Microbiologia e Imunologia - Instituto de Biociências, Universidade Estadual Paulista - UNESP.

Sob condições de assepsia e em câmara de fluxo laminar, as amostras foram colocadas em placas de Petri de $35 \mathrm{~mm}$ e lavadas com meio DMEM/F12 (Gibco - USA, suplementado com: $5 \mathrm{ml} / \mathrm{l}$ de vitaminas TC minimal Eagle $100 \mathrm{X}, 0,01 \mathrm{U} / \mathrm{ml}$ de insulina, 1,4 g/l de bicarbonato de sódio, $400.000 \mathrm{U} / \mathrm{ml}$ de penicilina, $40 \mathrm{mg} / \mathrm{ml}$ de gentamicina, $5 \mathrm{mg} / \mathrm{ml}$ de anfotericina-B, $15 \mu \mathrm{g} / \mathrm{l}$ de glutationa, com pH final de 7,0), para a remoção do excesso de células sanguíneas e, então, cortadas em fragmentos de aproximadamente $1 \mathrm{~mm}^{2} \mathrm{com}$ pinça e tesoura cirúrgicas delicadas e estéreis. Estes fragmentos foram colocados em frascos de poliestireno estéreis para cultura de células (TPP), com $1 \mathrm{ml}$ de meio DMEM/F12, suplementado com 15\% de soro fetal bovino (SFB) e mantidos em estufa a $37^{\circ} \mathrm{C}$ com $5 \%$ de $\mathrm{CO}_{2}$. A adição de meio DMEM/F12 com SFB a 15\% foi feita a cada 3 dias, com acompanhamento e exames das culturas sob microscópio de inversão, para a observação da morfologia e comportamento dos fibroblastos (aderência, migração e proliferação) até que se obtivesse um número satisfatório de células em cultura (Figura 1), definido pela observação de células com alta atividade mitótica e não confluentes, ocupando aproximadamente $2 / 3$ da capacidade do frasco, quando então, prosseguiu-se com a repicagem das células. Para o subcultivo das células, retirou-se o meio DMEM/F12 com SFB utilizando pipeta de Pasteur e realizou-se o enxágue cuidadoso dos frascos com solução PBS (Phosphate buffered saline) e a seguir os mesmos foram incubados com uma solução de EDTA (Gibco - USA) e tripsina (Instituto Adolfo Lutz), em estufa a $37^{\circ} \mathrm{C}$.

Com o microscópio de inversão, observou-se o desprendimento das células e então inativou-se a tripsina com a adição de meio

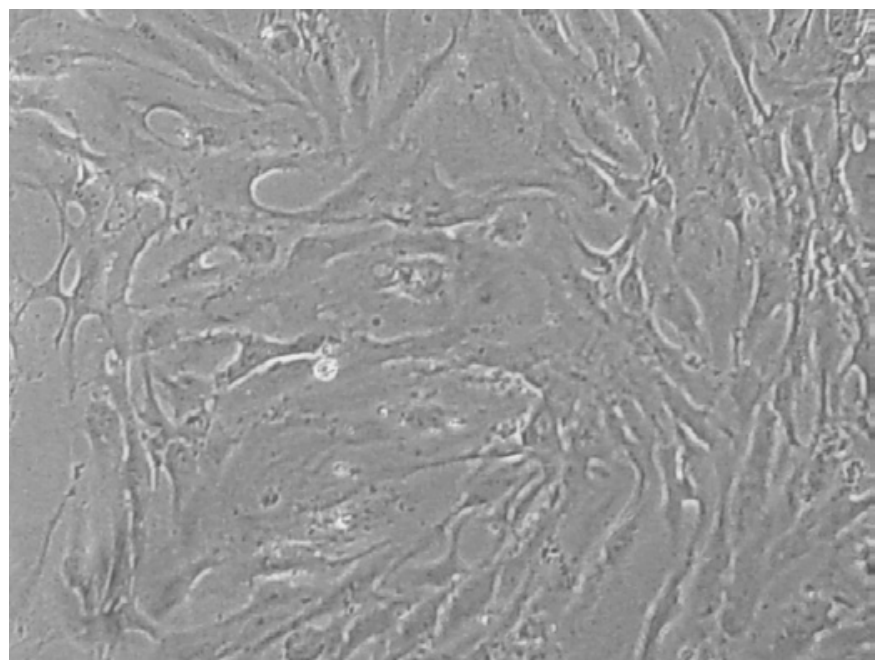

Figura 1. Fibroblastos em semiconfluência (aumento de 40x).
DMEM/F12, acrescido com 20\% de SFB. Esta suspensão celular foi então dividida em duas partes iguais, ficando uma no mesmo frasco e outra em um novo frasco estéril. Ambos foram colocados novamente em estufa até chegarem a semiconfluência, quando então foram novamente subcultivadas até se chegar ao terceiro subcultivo.

\section{EXPOSIÇÃO DAS CULTURAS À TRIANCINOLONA}

Foram selecionadas para exposição à triancinolona as amostras que alcançaram contagem suficiente para a distribuição igualitária em 16 do total de 24 poços dos multiwells, uma vez que o experimento foi realizado em triplicata com mais um controle para cada dia de contagem posterior à exposição à droga. Foram distribuídos 5.000 fibroblastos em cada poço da placa de cultivo.

Vinte e quatro horas após a distribuição das células nos multiwells, foi feita a exposição dos fibroblastos ao hexacetonido de triancinolona - 20 mg/mL (Triancil ${ }^{\circledR}$, Apsen), em triplicata, sendo mantido sempre um controle não exposto por dia de contagem. Todos os poços de cada amostra foram completados com 0,5 ml do meio de cultura DMEM/F12 acrescido com 20\% de SFB.

Imediatamente antes da exposição, o pH da solução de triancinoIona era de 7,66, ou seja, a solução era discretamente alcalina.

Após a exposição das células à droga, foram feitas as contagens em quatro momentos: 3, 6, 12 e 18 dias após.

O método para contagem de fibroblastos foi através de hemocitômetro (câmara de Neubauer). Em cada momento, foram contados os fibroblastos dos quatro poços, sendo 3 de culturas expostas e 1 de cultura controle não exposta.

Os dados obtidos foram analisados estatisticamente, utilizando a técnica de análise de Variância para o modelo de medidas repetidas para grupos independentes, segundo o esquema fatorial $2 \times 2$.

\section{RESULTADOS}

Apesar de ter sido colhido material de 14 indivíduos, o subcultivo celular foi possível em 8 cápsulas de Tenon de pterígios e em 6 cápsulas de Tenon normais, pois somente estas amostras apresentaram número de células suficientes para que o procedimento pudesse ser realizado em triplicata, além de se ter uma cultura controle para cada dia de contagem.

A tabela 1 mostra os valores da proliferação de fibroblastos de pterígios e da Tenon normal, com e sem a exposição à triancinolona. Foram feitas três comparações, todas representadas nesta mesma tabela por meio de letras, de forma que duas letras diferentes indicam significância:

1) Comparação das culturas de fibroblastos de pterígios ou da cápsula de Tenon quando expostas ou não expostas à droga, sendo a notação de significância estatística feita por meio de letras minúsculas (a e $\underline{b}$ ). Tanto as culturas de fibroblastos de pterígio, quanto as da Tenon normal, quando expostas à triancinolona, apresentaram crescimento celular significativamente menor (representado pela letra a minúscula) que as não expostas (representado pela letra $\underline{b}$ minúscula), em todos os momentos de observação.

2) Comparação da proliferação celular de fibroblastos de pterígio com os da cápsula de Tenon normal, representada por letras maiúsculas ( $\underline{A}$ e $\underline{B})$. Comparando-se a proliferação de fibroblastos de pterígio e da cápsula de Tenon normal, quando expostos e não expostos à triancinolona, os resultados foram semelhantes, ou seja, a triancinolona agiu sobre fibroblastos de pterígios e da cápsula de Tenon normal, reduzindo a proliferação celular. A única diferença significativa neste tipo de comparação foi observada aos 18 dias, quando os fibroblastos de pterígios não expostos à droga apresentaram taxa de proliferação maior que os fibroblastos da Tenon normal (observar que a letra $\underline{B}$ maiúscula se contrapõe à $\underline{A}$ maiúscula, apontando esta diferença aos 18 dias). 
Tabela 1. Mediana e semiamplitude do número de células segundo grupo, exposição e momento de avaliação

\begin{tabular}{lccccc}
\hline & & \multicolumn{4}{c}{ Momento avaliação } \\
\cline { 2 - 5 } Grupo & Exposição & $\mathbf{3}$ dias & $\mathbf{6}$ dias & $\mathbf{1 2}$ dias & $\mathbf{1 8}$ dias \\
\hline Pterígio & Sim & $3333 \pm 2000 \mathrm{aA} \alpha \beta$ & $2000 \pm 1333 \mathrm{aA} \alpha \beta$ & $667 \pm 667 \mathrm{aA} \alpha$ & $6000 \pm 4000 \mathrm{aA} \beta$ \\
& Não & $16000 \pm 2000 \mathrm{bA} \alpha$ & $38000 \pm 13000 \mathrm{bA} \beta$ & $28000 \pm 18000 \mathrm{bA} \beta$ & $90000 \pm \pm 43000 \mathrm{bB} \gamma$ \\
\multirow{2}{*}{ Normal } & Sim & $5333 \pm 4333 \mathrm{aA} \alpha$ & $2000 \pm 1667 \mathrm{aA} \alpha$ & $4833 \pm 3333 \mathrm{aA} \alpha$ & $2333 \pm 3232 \mathrm{aA} \alpha$ \\
& Não & $14000 \pm 4000 \mathrm{bA} \alpha$ & $29000 \pm 15000 \mathrm{bA} \beta$ & $49000 \pm 55000 \mathrm{bA} \beta$ & $34000 \pm 13000 \mathrm{bA} \beta$ \\
\hline
\end{tabular}

Para interpretação da tabela: letras minúsculas comparam grupo exposto ao não exposto, fixado grupo e momento de avaliação; letras maiúsculas comparam grupos nos diferentes momentos de avaliação; letras gregas comparam momento de avaliação, fixados grupo e exposição. Letras diferentes indicam diferença estatística.

3) Outra comparação apontada na tabela 1 por meio de letras gregas diz respeito à proliferação celular ao longo do tempo de experimentação. Observar que as culturas de fibroblastos de pterígio quando expostas à droga apresentaram inicialmente redução da proliferação celular; entretanto, na avaliação dos 18 dias houve retomada do crescimento, com diferença estatística (duas letras gregas diferentes mostram onde ocorreu a diferença significativa). As culturas de Tenon normal que foram expostas à droga se mantiveram com baixos índices de replicação por todo o experimento. Já as culturas que não foram expostas à droga, tanto de pterígios, quanto de Tenon normal, apresentaram crescimento crescente ao longo do período experimental.

\section{DISCUSSÃO}

O cultivo celular permite que se estude o efeito da droga, no caso a triancinolona, sem a interferência de fatores exógenos. Assim, o comportamento dos fibroblastos de pterígios e de cápsulas de Tenon normais sob efeito da droga em estudo, pode ser avaliado sem a influência de fatores ambientais sabidamente envolvidos na etiopatogenia do pterígio e em sua recorrência, tais como a exposição ao sol, ao vento ou a poeira. Desta forma, é possível estudar o real efeito de uma nova possibilidade terapêutica para o tratamento desta afecção que é tão comum em nosso meio.

Optou-se ainda por utilizar culturas primárias ao invés de linhagem celular, a fim de minimizar as influências intrínsecas inerentes à cada indivíduo doador.

Apesar de se ter estudado aqui apenas fibroblastos provenientes de portadores de pterígios recidivados, um estudo prévio já demonstrou que a resposta seria semelhante caso fossem incluídos pterígios primários, devido ao mesmo tipo de comportamento celular entre primários e recidivados in vitro(2).

A triancinolona é uma esteroide de ação intermediária que diminui a proliferação fibroblástica, formação de neovasos e inflamação. A possibilidade de ser injetada por via subconjuntival permite que uma concentração maior de corticosteroide seja aplicada diretamente na área de proliferação fibrovascular ${ }^{(3)}$.

A redução na proliferação celular sob efeito da triancinolona ocorreu na observação feita 3, 6 e 12 dias após a exposição, tanto nos pterígios recidivados como nas cápsulas de Tenon normais expostas à droga. A retomada da proliferação verificada 18 dias após a exposição nos fibroblastos de pterígios indica que a droga necessita de exposições mais frequentes, provavelmente em intervalos entre 12 e 18 dias, para que seja mantido seu efeito antiproliferativo que foi inicialmente observado. Estudo envolvendo o acetonida de triancinolona aplicado por via subconjuntival em pterígios recidivados, mostrou serem necessárias de uma a três injeções, com uma média de 3,4 semanas entre elas ${ }^{(4)}$ Estes achados clínicos corroboram com o presente estudo, realizado in vitro, que demonstrou que a triancinolona perdeu sua ação antiproliferativa, com volta da atividade fibroblástica na última avaliação (18 dias após a exposição).
Devido ao fato de não haver referências quanto ao uso da triancinolona em cultivo de fibroblastos de pterígio, optou-se por usá-la na mesma concentração encontrada comercialmente.

Segundo outro estudo(3) a triancinolona foi tão efetiva e segura quanto o 5-Fluoruracil na inibição da recorrência de pterígios. A maior complicação encontrada foi o aumento da pressão intraocular, porém reversível e controlável com medicações hipotensoras oculares, que puderam ser descontinuadas, sem nenhum dano ou glaucoma permanente. Porém estes autores utilizaram o acetonida de triancinolona, que é o mais potente dentre os corticosteroides de ação intermediária, sendo até oito vezes mais potente que a prednisona.

Em estudo anterior ${ }^{(5)}$ no qual foi comparada a eficácia do 5 -fluoruracil (5-FU) e da mitomicina C (MMC) sobre a inibição da proliferação fibroblástica, comprovou-se que ambas as drogas são igualmente eficientes a partir do sexto dia de exposição, com significância estatística. Porém a MMC, por ser um agente alquilante, age inibindo a proliferação de todas as células que porventura tenham entrado em contato com a droga, sejam estas células normais da conjuntiva e córnea adjacentes ou de fibroblastos de pterígios, o que não ocorre com a triancinolona ou o 5-FU. Porém, a triancinoIona apresentou eficácia antiproliferativa somente até o $12^{\circ}$ dia de exposição, enquanto o 5-FU pode manter-se efetivo por até 36 dias após a exposição(6).

Outras drogas como o Tacrolimus (FK 506) e a ciclosporina A já foram estudadas quanto à inibição da proliferação fibroblástica de pterígios ${ }^{(7,8)}$, mostrando-se também eficazes. Porém o FK 506 apresentou a retomada da proliferação após um dia de exposição, necessitando de reaplicações ainda mais frequentes que a triancinolona para manutenção da efetividade, enquanto a ciclosporina demonstrou maior variabilidade de resposta, uma vez que no $12^{\circ}$ dia de exposição, 2 dentre as 7 amostras apresentavam ainda fibroblastos viáveis.

Os resultados do presente estudo permitiram-nos verificar que a triancinolona in vitro realmente inibe a proliferação de fibroblastos de pterígios, assim como os da cápsula de Tenon normal. A redução desta proliferação se dá por período de tempo de 12 até 18 dias após a exposição à droga.

Fica claro que várias drogas podem ser utilizadas como tratamento adjuvante do pterígio, sendo necessário para cada uma delas observar o mecanismo de ação, a duração do efeito, o tempo de ação, as dosagens a serem aplicadas, a necessidade de repetições e o intervalo entre elas.

No caso da triancinolona, um conhecido agente antiproliferativo e anti-inflamatório, a efetividade como inibidor da proliferação de fibroblastos foi comprovada no presente estudo.

Novos estudos devem ainda ser realizados no sentido de definir qual o tipo de triancinolona (hexacetonida ou acetonida), a farmacodinâmica, a dose e a frequência da aplicação da droga, com o intuito de definir se a mesma pode ser útil como tratamento adjuvante do pterígio. 


\section{CONCLUSÃO}

Tanto os fibroblastos provenientes da cápsula de Tenon normal, quanto os de pterígios recidivados apresentaram taxa de proliferação significativamente menor após a exposição à triancinolona. No período de 18 dias, os fibroblastos de pterígio retomaram o crescimento. Os autores acreditam que a triancinolona pode ser uma boa alternativa como terapia adjuvante no tratamento do pterígio.

\section{REFERÊNCIAS}

1. Monteiro JV. A grande revolução. Universo Virtual. 2005(Maio):[cerca de 2 p.] [citado 2012 Jul 21]. Disponível em: http://www.universovisual.com.br/publisher/preview. php?edicao=0505\&id_mat=704

2. Viveiros MMH, Schellini SA, Rogatto SH, Rainho C, Padovani CR. Análise do cultivo de fibroblastos de pterígios primários e recidivados e da cápsula de tenon normal. Arq Bras Oftalmol. 2006:69(1):57-62.
3. Prabhasawat P, Tesavibul N, Leelapatranura K, Phonjan T. Efficacy of subconjunctival 5-fluorouracil and triamcinolone injection in impending recurrent pterygium Ophthalmology. 2006;113(7):1102-9

4. Paris FS, Farias CC, Melo GB, Santos MS, Batista JLA, Gomes JAP. Postoperative subconjuntival corticosteroid injection to prevent pterygium recurrence. Cornea. 2008 27(4):406-10

5. Viveiros MM, Schellini SA, J Candeias, CR Padovani. Exposição de fibroblastos da cápsula de Tenon normal de portadores de pterígio ao 5-fluorouracil e à mitomicina C. Arq Bras Oftalmol. 2007;70(1):73-7.

6. Khaw PT, Sherwood MB, MacKay SLD, Rossi MJ, Schultz G. Five minute treatments with fluorouracil, floxuridine, and mitomycin have long-term effects on human Tenon's capsule fibroblasts. Arch Ophthalmol. 1992;110(8):1150-4.

7. Carvalho CSC, Viveiros MMH, Schellini SA, Candeias JM, Padovani CR. Exposição de fibroblastos provenientes de pterígios recidivados e da cápsula de Tenon normal ao tacrolimus (FK506). Arq Bras Oftalmol. 2007;70(2):235-8.

8. Hércules LA, Viveiros MMH, Schellini SA, Candeias J, Padovani CR. Exposição de fibroblastos da cápsula de Tenon de pterígios à ciclosporina 0,05\%. Arq Bras Oftalmol. 2006;69(6):831-5.

\title{
VII Congresso Brasileiro de Catarata e Cirurgia Refrativa V Congresso Brasileiro de Administração em Oftalmologia
}

\section{9 de maio a 1을 junho de 2013}

\author{
Hotel Iberostar Bahia
}

Praia do Forte (BA)

\section{Informações:}

Site: www.catarataerefrativa2013.com.br 